\title{
Efficacy of gluten- and casein-free diets on autism spectrum disorders in children
}

Eman S. Alamri, $M S c$, PhD.

\begin{abstract}

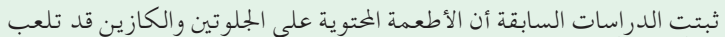

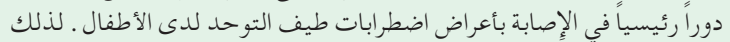

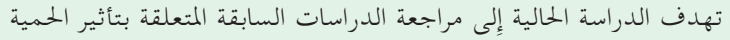

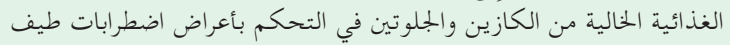

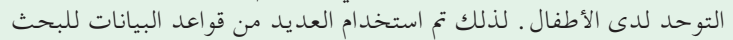

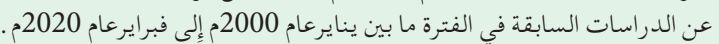

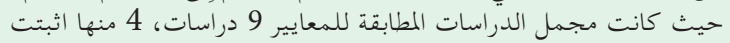

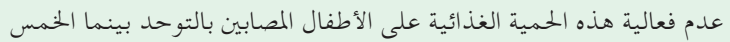

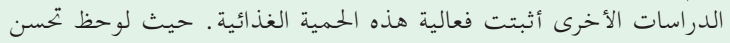

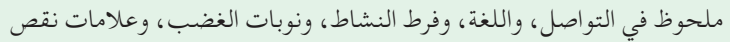

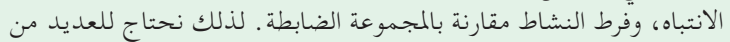

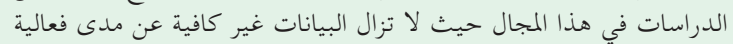

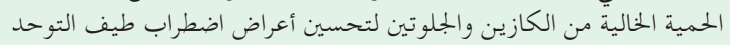

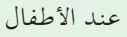

Food containing gluten and casein could play a role in autism spectrum disorders (ASD) symptoms. The present review aimed to update the evidence about the role of the gluten- and casein-free diet (GCFD) on the management of ASD. Web of Science, Science Direct, Google Scholar, and PubMed databases were used to search for randomized controlled trials (RCT) conducted between January 2000 and February 2020. In total, 9 RCT were included (521 participants) with age range between 2 to 18 years. Four of these studies did not show a significant improvement regarding the symptoms of ASD. The rest of these studies $(n=5)$ showed improvement in communication, stereotyped movements, aggressiveness, language, hyperactivity, tantrums, and signs of attention deficit hyperactivity disorder compared to control group. Hence, the data remains insufficient to support the use of GCFD to improve the symptoms of ASD in children.

Keywords: GCFD, ASD, review, dietary intervention

Saudi Med J 2020; Vol. 41 (10): 1041-1046 doi: 10.15537/smj.2020.10.25308

From the Department of Nutrition and Food Science, Faculty of Home Economics, University of Tabuk, Tabuk, Kingdom of Saudi Arabia.
Address correspondence and reprint request to: Dr. Eman S. Alamri, Department of Nutrition and Food Science, Faculty of Home Economics, University of Tabuk, Tabuk, Kingdom of Saudi Arabia. E-mail:ialamri@ut.edu.sa

ORCID ID: https://orcid.org/0000-0001-5113-0495

A utism spectrum disorders (ASD) is defined as neurodevelopmental disorder that is usually diagnosed in the first 3 years of life. ${ }^{1}$ This disorder is characterized by difficulties in social communication, social interaction, and restricted activity. ${ }^{2}$ According to data obtained from the World Health Organization, one in 160 children have ASD. ${ }^{2}$ In the last 2 decades, the number of diagnosed cases of ASD grew dramatically. ${ }^{3}$ The etiology of ASD is unknown. Although genetic factors play a crucial role in the a etiology of ASD, they alone cannot explain the noticeable raise in the incidence of ASD. ${ }^{4}$ Environmental factors, including nutritional factors, may have contribution in this issue. ${ }^{5}$

A deficiency in omega-3 fatty acids was reported among children with ASD. ${ }^{6}$ A review demonstrated that no firm conclusions could be drawn due to the small number of participants included. ${ }^{7}$ Food containing gluten and casein could play a role in ASD symptoms. 8 , This is due to gastrointestinal problems, such as celiac disease, that often occur in ASD patients. ${ }^{10}$ Celiac disease is defined as a sensitivity to gluten and considered a digestive disorder that damages the small intestine. ${ }^{11}$ The consumption of food containing gluten or casein could trigger this disease. ${ }^{12}$ Researchers hypothesized that this protein metabolism abnormality could alter the function of the central nervous system through its massive opioid activity. ${ }^{13}$ In addition, increases the intestinal permeability, which increases the ability of gluten to pass into the bloodstream and the central nervous system. ${ }^{14}$ These mechanisms, along with metabolic defect, could contribute to the incidence of ASD and its symptoms. ${ }^{15}$ Thus, a gluten-and casein-free diet (GCFD) could be beneficial and effective for reducing the symptoms of ASD patients. 
A previous review carried out in 2018 involved 6 randomized controlled trials (RCT) to examine the efficacy of a GCFD on ASD symptoms. It concluded that there was inconsistent evidence supporting the usage of GCFD for ASD children. ${ }^{16}$ Another review indicated that there was not sufficient evidence to confirm a positive effect of a GCFD on ASD.${ }^{17} \mathrm{~A}$ recent review indicated that data regarding the effectiveness of GCFD for ASD children were inconsistent and insufficient. ${ }^{18}$ Therefore, this present review aimed to update the evidence regarding the role of GCFD on the management of ASD, as it hypnotized that GCFD can make improvements in some traits related to ASD.

Search strategy. This review only included RCT that focused on the effect of a GCFD or both of them together. Children were diagnosed with ASD based on criteria described previously. ${ }^{19,20}$ The criteria mentioned by $\mathrm{WHO}$ were also considered in this review. ${ }^{21}$ Other criteria for inclusion in this review were to compare the effect of GCFD to a normal diet. Several databases were used for searching (PubMed, Science Direct, Web of Science, and Google Scholar). All studies written in Arabic or English and conducted between January 2000 and February 2020 were included in this review. Many terms were used during searching, including casein-free diet, gluten-free diet OR dairy-free diet, and autism spectrum disorder, ASD, OR autism. The articles were initially screened by the authors through the abstract, title, and keywords of every article. If the article was potentially relevant or the relevance was unclear, the full text was retrieved. The data were extracted using standard data-extraction forms. Any study not written in Arabic or English were excluded from the review or were not a comparative study. Also, studies which the author had not access to the full text or duplicate studies which was found more than once on different databases were excluded. Studies which had previously published in abstract form were also excluded.

The initial search yielded 301 articles and only 9 articles met the criteria to be included in this review. Figure 1 presents the process for the included articles. The total number of participants recruited were 521 (256 in the intervention groups and 265 in the control groups) with age range between 2 to 18 years. The duration of intervention varied between the studies, it ranged between 7 days and 2 years. The location of

Disclosure. Authors have no conflict of interests, and the work was not supported or funded by any drug company. these studies were varied, with $50 \%$ conducted in the United States (US) $(n=4)$. The rest of the studies were conducted in Indonesia $(\mathrm{n}=1)$, Denmark $(\mathrm{n}=1)$, Norway $(\mathrm{n}=1)$, Iran $(\mathrm{n}=1)$, and Poland $(\mathrm{n}=1)$.

Effect of intervention. We found that 4 RCT examined a GCFD and 2 RCT examined the role of a gluten-free diet. Four of them did not show a significant improvement regarding the symptoms of ASD. Five studies showed improvement in aggressiveness, language, hyperactivity, stereotyped movements, tantrums, communication, and attention.

Two studies demonstrated a significant improvement in ASD symptoms post the intervention. ${ }^{22,23}$ One study revealed that the caregivers of 7 children reported that there was a noticeable reduction in hyperactivity and decreased tantrums as well as improvements in the child's language. ${ }^{22}$ However, there was no significant difference between the intervention and controlled groups in the urinary peptide levels of gluten and casein. ${ }^{22}$ Findings from other RCT revealed an improvement in the GCFD group in communication score as well as social interactions. ${ }^{23}$ Gluten-free and casein-free (GFCF) group showed an improvement in the score of 'daily living skills' based on caregiver's reports. Finally, the scores for the 'inattention and hyperactivity' showed statistically significant improvements in the GFCF group. $^{23}$

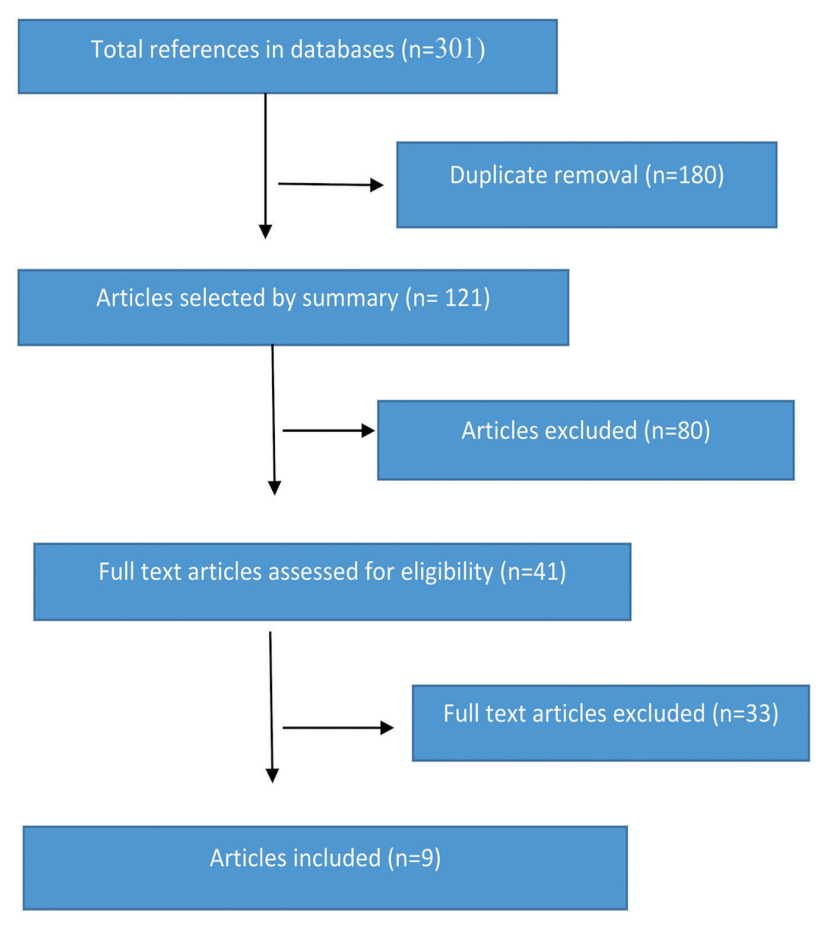

Figure 1 - Flowchart of the selection of studies for review. 
Another RCT showed remarkable improvement in autistic syndromes after one year of gluten-free intervention. The researchers showed a reduction in the resistance to learning, including behaviors such as closing the eyes, turning away from the teacher, plain indifference, and covering the ears. In addition, they showed an improvement in their responses to learning, aloofness, peer relationship, routines, and rituals. There was a drastic reduction in unusual emotions, such as extreme anxiety and laughing when other people cried. ${ }^{24}$ However, these improvements could attributed to other factors along with diet as this study depend on the observations of caregivers and teachers.

One trial measured changes in several aspects for ASD children, including cognitive functioning (such as, receptive language, visual reception, fine motor skills, and gross motor skills, expressive language), child behavior (example, attention problems, anxious, withdrawn, depressed, emotional regulation, somatic complaints, aggressive behaviors), and gastrointestinal symptoms (irregular bowel, diarrhea, and constipation). The results showed that the intervention group fed with the GCFD has a significant improvement in aspects, such as the visual reception, the withdrawn state and a reduction in aggression after the 3-month follow-up. ${ }^{25}$ Ghalichi et $\mathrm{al}^{26}$ demonstrated that gluten free diet for 6 weeks were effective in improving in stereotyped behaviors, communication, and social interaction in intervention group compared to control group.

Four RCT showed no significant improvements in ASD symptoms. ${ }^{27-30}$ In one study, the participants were assessed 3 times pre-intervention, after 6 months, and then after 12 months of consuming GCFD. Post the intervention has no significant change in behaviors, such as, language, sociability, sensory speech communication, cognitive awareness, autistic isolation, impairment of physical health. ${ }^{27}$

Another study compared the effect of a glutencontaining diet with gluten free diet on children with ASD behavior. The intervention lasted for 8 weeks and there was a follow up 6 months after the intervention. The results indicated that there were no differences between the groups regarding ASD symptoms post intervention such as intellectual abilities or maladaptive behaviors. ${ }^{28}$ The other 2 RCT measured, nausea, abdominal pain, abdominal bloating diarrhea, vomiting, and constipation along with other ASD symptoms including cognitive skills, linguistic abilities, motor abilities, emotional regulation, anxiousness, and depression. ${ }^{29,30}$ Table 1 summarizes the characteristics of all studies included in the current review. The current review aim to collect updated evidence regarding the role of GCFD on the management of ASD.
Discussion. We included 9 RCT that were published in the last 2 decades between January 2000 and February 2020. The results showed that there was little evidence demonstrating the GCFD was beneficial in managing the symptoms of ASD in children and adolescents. However, some studies revealed that the GCFD was not effective in improving the symptoms of ASD among children and adolescents and no significant differences were detected between the intervention and control groups.

Similar results were reported in some previous reviews. Navarro et $\mathrm{al}^{29}$ conducted a review which included studies between 1985 and 2007, and included 2 small RCT that included, in total, 35 participants and lasted between 2 to 12 months. These 2 RCT demonstrated significant improvements in social isolation, and the overall ability to communicate and interact among ASD children. ${ }^{31}$ However, the number of studies were insufficient to conclude the effect of a GCFD. The most recent review included studies between 2003 and 2019 with a total of 9 RCT with ages ranging between 2 to 18 years and the duration ranging from a week to 2 years. The review revealed that only 3 studies out of 9 showed improvement in autistic behaviors. ${ }^{32}$ Another review included studies between 2005 to February 2015 and 5 RCT met the criteria. That review showed mix and inconsistent results. ${ }^{33}$ In addition, Sathe et $\mathrm{al}^{34}$ demonstrated that only 4 studies out of 9 showed improvements in language, social isolation, communication, repetitive, cognitive skills and, anxiety. Previous study ${ }^{34}$ in conjunction with the current study, indicates an increased interest in GCFD treatments for ASD over the past decade.

Care should be taken when establishing GCFD for children with ASD and should provide training programs and adequate information to their families. It is recommended to educate their families at least 3 hours. $^{34}$

Study limitations. There are some limitations that can influence the outcomes, such as heterogeneous groups, including variations in the degree of autism, gender, and age, as well as short durations of intervention. Using different multiple methods in assessing outcomes was another limitation in this study as this resulted in a lack of standardization among the studies. Some articles assessed the effectiveness of the intervention and behavioral variables through observation of teachers or caregivers, which can influence the outcomes as this can be distorted over time. In additional limitation is that there was no consensus regarding the administered supplement doses for ASD children. The current study only include comparative studies and did not include 
Table 1 - Summary of the studies included in the study.

\begin{tabular}{|c|c|c|c|c|c|}
\hline Reference number & Duration & Ages & Sample size & Outcomes measured & Outcome \\
\hline 22 (United States) & 3 months & $2-16$ & 15 & $\begin{array}{l}\text { Communication, relationships with others, } \\
\text { activity level, tactile responsiveness, emotional } \\
\text { expression, resistance to change, visual, auditory, } \\
\text { social interaction, anxiety, repetitive behaviors } \\
\text { urinary peptide levels, intellectual ability, home } \\
\text { observation such as child responding. }\end{array}$ & $\begin{array}{l}\text { Only } 7 \text { children showed } \\
\text { improvements in child language, } \\
\text { decreased hyperactivity and } \\
\text { decreased tantrums. }\end{array}$ \\
\hline 23 (Norway) & 12 months & $5-10$ & 10 & $\begin{array}{l}\text { Emotions sharing, peculiar gait or movements, } \\
\text { repetitive, interaction with other children, eye } \\
\text { contact, echolalia, language, anxiety, attachment } \\
\text { to particular items, adult dependency, cognitive } \\
\text { skills, linguistic abilities, and motor abilities. } \\
\text { Communication, fear, physical contact, } \\
\text { emotional expressions, rigidity peculiar handling } \\
\text { toys. }\end{array}$ & $\begin{array}{l}\text { A reduction in resistance to learning } \\
\text { (example, closing the eyes, turning } \\
\text { away from the teacher, covering the } \\
\text { ears). Improve in peer relationship, } \\
\text { routines and rituals. }\end{array}$ \\
\hline 24 (United States) & 3 months & $3-5$ & 8 & $\begin{array}{l}\text { Intellectual development example, language and } \\
\text { motor skills } \\
\text { Child behavior: anxious, withdrawn, aggressive, } \\
\text { attention } \\
\text { Sastrointestinal symptoms: irregular bowel, } \\
\text { diarrhea, constipation }\end{array}$ & $\begin{array}{l}\text { Only improvement in aggression } \\
\text { and the withdrawn factor }\end{array}$ \\
\hline 25 (Denmark) & 24 months & $4-10$ & 72 & $\begin{array}{l}\text { Language capability, communication, social } \\
\text { interaction, repetitive behaviors, inattention and } \\
\text { hyperactivity, and daily living skills }\end{array}$ & $\begin{array}{l}\text { Improvement in daily living skills, } \\
\text { inattention and hyperactivity. }\end{array}$ \\
\hline 26 (Iran) & 6 weeks & $4-16$ & 80 & $\begin{array}{l}\text {-Gastrointestinal outcome: diarrhea } \\
\text {-Behavioral outcomes: social interaction, } \\
\text { communication }\end{array}$ & $\begin{array}{l}\text { Improvement in stereotyped } \\
\text { behaviors, communication, and } \\
\text { social interaction in intervention } \\
\text { group compared to control group }\end{array}$ \\
\hline 27 (United States) & 6 months & $2-18$ & 37 & $\begin{array}{l}\text { Social withdrawal, language, sociability, sensory, } \\
\text { communication autistic isolation, speech, } \\
\text { physical health and behavior, motor disturbances, } \\
\text { hyperactivity items, disturbances in attention, } \\
\text { perception, intellectual functions, inappropriate } \\
\text { emotional. } \\
\text { Irritability, affective responses, stereotypic } \\
\text { behavior, inappropriate speech, cognitive } \\
\text { awareness } \\
\text { Urinary concentrations of beta-casomorphin }\end{array}$ & $\begin{array}{l}\text { No significant difference between } \\
\text { groups. }\end{array}$ \\
\hline 28 (Poland) & 2 months & $3-6$ & 28 & $\begin{array}{l}\text { Intellectual abilities, socialization, cognitive } \\
\text { abilities, communication, social functioning, } \\
\text { restricted and repetitive behaviors. }\end{array}$ & $\begin{array}{l}\text { No significant difference between } \\
\text { groups. }\end{array}$ \\
\hline 29 (United States) & 1 month & $4-7$ & 6 & $\begin{array}{l}\text { Hyperactivity, withdrawn, irritability, and } \\
\text { inattention, depressed, abdominal pain, vomiting, } \\
\text { bowel movements, cognitive skills, linguistic } \\
\text { abilities, motor abilities, anxious, aggressive } \\
\text { behaviors }\end{array}$ & $\begin{array}{l}\text { No significant difference between } \\
\text { groups. }\end{array}$ \\
\hline 30 (Indonesia) & 7 days & $4-7$ & 38 & $\begin{array}{l}\text { Diarrhea, urinary creatinine levels, constipation, } \\
\text { abdominal bloating, vomiting, fears, perceptual } \\
\text { behaviors, flatulence, social problems, } \\
\text { aggressiveness, abdominal pain, resistance to } \\
\text { change, regulation problems, nausea }\end{array}$ & $\begin{array}{l}\text { No significant difference between } \\
\text { groups. }\end{array}$ \\
\hline
\end{tabular}


unpublished data, which could negatively influence the number of references analyzed. Another limitation was to include studies written in Arabic or English only.

Thus, future studies should include larger sample sizes; the length of the study should be more than 6 months and the patients should be checked if they suffer from celiac disease or food allergies before the intervention. It is better to make a sub-group for GCFD dietary interventions (example, those who have inflammation of the gastrointestinal abnormality) as they could have a better response to this type of intervention. There are several factors that should be considered as they could affect the efficacy of a GCFD, including the nutritional status of the participants, food sensitivities and allergies, physiological abnormalities, the burden on the family, including cost of a GCFD, and time commitments.

In conclusion, the current study designed to update and resolve uncertainty regarding the role of a GCFD in children with ASD. Although some studies showed progress in certain traits related to ASD after a GCFD, the data remains inconsistent and insufficient in terms of quantity and quality. This is due to the differences in methods used in these studies, which made it difficult to interpret them. It is difficult to conduct a well-controlled GFCF dietary trial; however, these are crucial to informing clinical treatment decisions. These results can assist clinician decision-maker and caregiver on the role of this type of therapies for children with ASD.

Acknowledgment. The authors gratefully acknowledge MDPI (www.mdpi.com/authors/english) for English language editing.

\section{References}

1. Doernberg E, Hollander E. Neurodevelopmental disorders (ASD and ADHD): DSM-5, ICD-10, and ICD-11. CNS Spectr 2016; 21: 295-299.

2. World Health Organization. Autism spectrum disorders. [Updated 2020. Accessed 2020 March 31]. Available from ULR: http://www.who.int/mediacentre/factsheets/autismspectrum-disorders/en/

3. Center for Diseases Control and Prevention. Data \& Statistics on Autism Spectrum Disorder. [Updated 2016. Accessed 2020 March 31]. Available from URL: https://www.cdc.gov/ncbddd/ autism/data.html

4. Rybakowski F, Chojnicka I, Dziechciarz P, Horvath A, Janas-Kozik M, Jeziorek A, et al. The role of genetic factors and pre-and perinatal influences in the etiology of autism spectrum disorders-indications for genetic referral. Psychiatr Pol 2016; 50: 543-554

5. Bölte S, Girdler S, Marschik P. The contribution of environmental exposure to the etiology of autism spectrum disorder. Cell Mol Life Sci 2019; 76: 1275-1297.
6. Ooi Y, Weng S, Jang L, Low L, Seah J, Teo S et al. Omega-3 fatty acids in the management of autism spectrum disorders: findings from an open-label pilot study in Singapore. Eur J Clin Nutr 2015; 69: 969-971.

7. Horvath A, Lukasik J, Szajewska H. $\omega-3$ fatty acid supplementation does not affect autism spectrum disorder in children: a systematic review and meta-analysis. J Nutr 2017; 147: 367-376.

8. Cekici H, Sanlier N. Current nutritional approaches in managing autism spectrum disorder: a review. Nutr. Neurosci 2019; 22: 145-155.

9. Sumathi T, Manivasagam T, Thenmozhi A. The Role of Gluten in Autism. In: Essa M, Qoronfleh M, editors. Personalized Food Intervention and Therapy for Autism Spectrum Disorder Management. Switzerland (AG): Springer. 2020.

10. Juneja M, Venkatakrishnan A, Kapoor S, Jain, R. Autism spectrum disorders and celiac disease: is there an association? Indian Pediatr 2018; 55: 912-914.

11. Kelly P, Bai C, Liu E, Leffler A. Advances in diagnosis and management of celiac disease. Gastroenterology 2015; 148: 1175-1186

12. Elli L, Branchi F, Tomba C, Villalta D, Norsa L, Ferretti F, et al. Diagnosis of gluten related disorders: eliac disease, wheat allergy and non-celiac gluten sensitivity. World J. Gastroenterol 2015; 21: 7110-7119.

13. Delgado A, Fochesato A, Juncos I, Gargiulo Á. Metabolic Association Between the Gut-Brain Axis in Autism Spectrum Disorders. In: Gargiulo P, Mesones-Arroyo H, editors.Psychiatry and Neuroscience Update - Vol. II. Switzerland (AG): Springer. 2017.

14. Doenyas, C. Gut microbiota, inflammation, and probiotics on neural development in autism spectrum disorder. Neuroscience 2018; 374: 271-286.

15. Frye RE. Metabolic and mitochondrial disorders associated with epilepsy in children with autism spectrum disorder. Epilepsy Behav 2015; 47: 147-157.

16. Piwowarczyk A, Horvath A, Łukasik J, Pisula E, Szajewska H. Gluten-and casein-free diet and autism spectrum disorders in children: a systematic review. Eur J Nutr 2018; 57: 433-440.

17. Perez J. Literature review: the effects of a gluten and casein free diet on children with autism spectrum disorder [dissertation]. Merced (CA): University of Califonia Merced; 2019.

18. Reissmann A. Gluten-free and casein-free diets in the management of autism spectrum disorder: A systematic literature review. MNHD 2020; 4: 21-38.

19. First MB. Diagnostic and Statistical Manual of Mental Disorders (DSM-IV). 4th ed. Washington (DC): American Psychiatric Association; 1994.

20. Guze SB. Diagnostic and Statistical Manual of Mental Disorders. Text Revision (DSM-IV-TR). 4th ed. Washington (DC): American Psychiatric Association; 2000.

21. World Health Organization. Manual of the International Statistical Classification of the Diseases and Related Health Problems. 10th ed. [Updated 2016. Accessed 2020 February]. Available from URL: http://www.who.int/classifications/icd/ en/

22. Elder J, Shankar M, Shuster J, Theriaque D, Burns S, Sherrill L. The gluten-free, casein-free diet in autism: results of a preliminary double blind clinical trial. J Autism Dev Disord 2006; 36: 413-420. 
23. Whiteley P, Haracopos D, Knivsberg A, Reichelt K, Parlar S, Jacobsen J et al. The ScanBrit randomised, controlled, singleblind study of a gluten- and casein-free dietary intervention for children with autism spectrum disorders. Nutr Neurosci 2010; 13: 87-100.

24. Knivsberg A, Reichelt K, Høien T, Nødland M. A randomised, controlled study of dietary intervention in autistic syndromes. Nutr Neurosci 2002; 5: 251-261.

25. Johnson C, Handen B, Zimmer M, Sacco K, Turner K. Effects of gluten free/casein free diet in young children with autism: a pilot study. J Dev Phys Disabil 2011; 23: 213-225.

26. Ghalichi F, Ghaemmaghami J, Malek A, Ostadrahimi A. Effect of gluten free diet on gastrointestinal and behavioral indices for children with autism spectrum disorders: a randomized clinical trial. World J Pediatr 2016; 12: 436-442.

27. González-Domenech P, Atienza F, Pablos G, Soto M, Martínez-Ortega J, Gutiérrez-Rojas L. Influence of a combined gluten-free and casein-free diet on behavior disorders in children and adolescents diagnosed with autism spectrum disorder: a 12-month follow-up clinical trial. J Autism Dev Disord 2020; 50: 935-948.

28. Piwowarczyk A, Horvath A, Pisula E, Kawa R, Szajewska, H. Gluten-free diet in children with autism spectrum disorders: a randomized, controlled, single-blinded trial. J Autism Dev Disord 2020; 50: 482-490.
29. Navarro F, Pearson DA, Fatheree N, Mansour R, Hashmi SS, Rhoads JM. Are 'leaky gut' and behavior associated with gluten and dairy containing diet in children with autism spectrum disorders? Nutr Neurosci 2015; 18: 177-185.

30. Millward C, Ferriter, M, Calver J,Connell-Jones G. WITHDRAWN: Gluten-and casein-free diets for autistic spectrum disorder. The Cochrane database of systematic reviews, 2019 4: CD003498-CD003498.

31. Monteiro M, Santos A, Gomes L, Rito R. Autism spectrum disorder: a systematic review about nutritional interventions. Revista Paulista de Pediatria 2020; 38: e2018262.

32. Elder J, Kreider C, Schaefer N, de Laosa, M. A review of gluten-and casein-free diets for treatment of autism: 2005-2015. Nutr Diet Suppl 2015; 7: 87-101.

33. Goday P. Whey watchers and wheat watchers: the case against gluten and casein in autism. Nutrn Clinic Pract 2008; 23: 581-592.

34. Sathe N, Andrews J, McPheeters L, Warren Z. Nutritional and dietary interventions for autism spectrum disorder: a systematic review. Pediatrics 2017 139: e20170346. 